\title{
Complexidade e currículo: por uma nova relação
}

\section{Maria Cândida Moraes*}

\begin{abstract}
Resumo: Neste ensaio, advoga-se a necessidade de se repensar as questões curriculares a partir da teoria da complexidade, justificando a importância desse instrumento para evitar a visão positivista de currículo, que separa disciplinas, fragmenta objeto do conhecimento, a realidade e a vida. Para tanto, são trabalhados os conceitos de currículo e de complexidade, reconhecida em seus aspectos ontológico, epistemológico e metodológico, bem como a importância da relação currículo/complexidade e alguns de seus possíveis desdobramentos em educação. Observa-se que a teorização complexa do currículo ajuda a repensá-lo a partir da pluralidade cultural, da unidade na diversidade, da capacidade de produzir coisas novas no processo a partir de processos emergentes. Para tanto, considera-se a intersubjetividade e multirreferencialidade, reafirma-se a importância da alteridade, da luta pela afirmação das diferenças, bem como dos processos auto-eco-organizadores resultantes dos diálogos ocorrentes em sala de aula. O conhecimento interdisciplinar ou transdisciplinar decorrentes desta relação, em seus papéis formativo e elucidativo, são fundamentais ao mobilizar os processos de interdependência, de mestiçagem, de interfecundação e de religação de saberes. Assim compreendido, o currículo transforma-se no espaço da solidariedade epistêmica, da emergência e mudança de valores, diante da multiplicidade e heterogeneidade das experiências que requerem a superação da fragmentação disciplinar e a presença do diálogo constante. Ao finalizar, a autora ressalta a importância de se desenvolver, através das práticas curriculares, a reforma do pensamento proposta por Edgar Morin, a partir da inteligência da complexidade, como condição fundamental para superação da fragmentação do conhecimento e o encontro de soluções compatíveis à magnitude dos problemas atualmente emergentes.
\end{abstract}

Palavras-chave: complexidade, currículo, transdisciplinaridade

\section{Complejidad y currículo: por una nueva relación}

Resumen: Este ensayo aboga por la necesidad de repensar las cuestiones curriculares a partir de la teoría de complejidad, justificando la importancia de este instrumento para evitar la visión positivista del currículo, que separa disciplinas, fragmenta el objeto de conocimiento, la realidad y la vida. Para alcanzar este objetivo, son trabajados los conceptos de currículo y de complejidad, reconocida en sus aspectos ontológico, epistemológico y metodológico, así como la importancia de la relación currículo/ complejidad y algunos de sus resultados posibles en la educación. Se observa que la teorización compleja del currículo ayuda a repensarlo a partir de la pluralidad cultural, de la unidad en la diversidad, de la capacidad de producir cosas nuevas cosas a partir de procesos emergentes. Por consiguiente, la intersubjetividad y la multireferencialidad reafirman la importancia de la alteridad,

*Universidad Católica de Brasilia, Distrito Federal, Brasil. Email: mcmoraes@terra.com.br 
de la lucha por la afirmación de las diferencias, así como de los procesos auto-ecoorganizadores resultantes de los diálogos que ocurren en el aula. El conocimiento interdisciplinario o transdisciplinario que es resultado de esta relación, en sus papeles formativo y elucidativo, son esenciales para movilizar los procesos de interdependencia, de mestizaje, de interfecundación y de religación de saberes. Así entendido, el currículo se transforma en el espacio de solidaridad epistémica, de emergencia y de cambio de valores, dados la multiplicidad y la diversidad de las experiencias que requieren la superación de la fragmentación disciplinaria y la presencia del diálogo constante. Para concluir la autora acentúa la importancia de desarrollar, mediante las prácticas curriculares, la reforma del pensamiento propuesta por Edgar Morin, a partir de la inteligencia de complejidad, como condición fundamental para superar la fragmentación del conocimiento y encontrar soluciones compatibles a la magnitud de los problemas actualmente emergentes.

Palabras clave: complejidad, currículo, transdisciplina

\section{Complexity and curriculum: for a new relationship}

This essay advocates the need to rethink curricular issues starting from the complexity theory. It explains the importance of this instrument to avoid the positivist views of curriculum, which separates disciplines, and fragments the object of knowledge, reality and life. To achieve this goal, the concepts of curriculum and complexity are developed acknowledging its various aspects that include ontological, epistemological and methodological views, as well as the importance of the relationship curriculum/complexity and some of its possible outcomes in education. It is observed that the complexity theorization of the curriculum helps to rethink it starting from cultural plurality, unity in diversity, ability to produce new things from emerging processes. Thus, the inter-subjectivity and multiple references reaffirms the importance of otherness, the struggle for the affirmation of differences, as well as the self-eco-organizatory processes as result of classroom dialogue. The interdisciplinary and transdisciplinary knowledge resulting from this relationship, in their roles and meaningful training, are essential to mobilize the processes of interdependence, cross-breeding and reconnection of knowledge. Thus understood, the curriculum becomes the epistemic space of solidarity, emergency and change of values, given the multiplicity and diversity of experiences that require overcoming the disciplinary fragmentation and the presence of constant dialogue. In conclusion, the author emphasizes the importance of developing, through curriculum practices, the "thinking reform" proposed by Edgar Morin, starting from the intelligence of complexity, as a precondition for overcoming the fragmentation of knowledge and finding solutions compatible to the magnitude of the problems now emerging.

Key words: complexity, curriculum, transdiscipline

Recibido: 15.01 .2010

Aceptado: 15.02.2010

$* * *$

\section{Introdução}

Como repensar as questões curriculares a partir da complexidade? Por que é importante se trabalhar o currículo a partir do Pensamento Complexo? O que significa assumir um currículo numa perspectiva da 
complexidade? Que implicações decorrem em relação às formas de organização escolar e às praticas pedagógicas? Qual é o significado para o currículo desta célebre frase de Pascal: "sendo todas as coisas ajudadas e ajudantes, causadas e causante, estando tudo ligado por um laço natural e invisível, considero impossível conhecer as partes sem conhecer o todo, como também considero impossível conhecer o todo sem conhecer particularmente as partes?” (Morin, 1990 p.148). Que reflexões esta frase nos sugere para repensarmos as questões curriculares?

Ora, inúmeras são as questões que surgem ao iniciar esta reflexão temática. Certamente, não teremos todas as respostas, mas consideramos de fundamental importância aprofundar um pouco mais esta discussão, tendo em vista sua repercussão nos processos educacionais e na maneira de se pensar a educação em nossos países. Além disto, acreditamos que é fundamental lançar algumas sementes de mudança no cenário educacional latino-americano e, mais precisamente, no pensamento curricular brasileiro, mas com o necessário rigor acadêmico e a fecundidade requerida pelo pensamento científico ao abordar esta questão.

Uma das razões que queremos destacar é sobre a importância de nos comprometermos com o desenvolvimento de uma aprendizagem que verdadeiramente garanta competência e formação cidadã e que favoreça a reforma de pensamento almejada por Edgar Morin, mediante o aprimoramento de nossa capacidade de reflexão e maior consciência sobre a problemática que nos cerca, a partir de uma discussão conectada com os grandes desafios que a contemporaneidade nos apresenta.

Por outro lado, estamos também convencidos de que já não podemos continuar deixando a responsabilidade maior pelas definições mais importantes no campo das políticas públicas e das práticas educacionais na mão dos burocratas da educação e dos tecnocratas de plantão, com seus pensamentos reducionistas e que pouco ou nenhum compromisso têm com as questões educacionais ou com um currículo verdadeiramente educativo. Os processos de formação por eles suscitados ou promovidos pouco compromisso têm com a evolução da consciência humana e, mais precisamente, com a consciência cidadã. Seus interesses certamente são outros. Os problemas educacionais são, acima de tudo, problemas humanos que afetam e integram processos de criação, de recriação e manutenção da vida. É importante reconhecer, portanto, que a educação não implica apenas um serviço a ser prestado e nem uma mercadoria qualquer a ser vendida, mas um direito humano inalienável, inseparável da natureza biopsicossocial do ser humano e, portanto, não redutível a aspectos burocráticos e tecnocráticos.

Assim, quanto maior o número de educadores ou de pessoas implicadas e capacitadas e em condições de discutir as questões curriculares, melhor será para todos nós, no sentido de promover os diálogos e as transformações educacionais necessárias para que ocorra a descolonização no âmbito das propostas curriculares. A grande maioria dos currículos ainda continua sendo um artefato educacional dos mais autoritários, excludentes 
e prepotentes na mão de educadores positivistas e políticos oportunistas, descomprometidos com a realidade social e com o trabalho que desenvolvem. Isto vem contra as necessidades atuais que requerem sujeitos ativos, conscientes, críticos, criativos, amorosos, generosos, responsáveis, comprometidos socialmente e, cada vez, mais reflexivos e atuantes no cenário educacional.

Já não podemos continuar com a visão simplista do conhecimento limitada à transmissão de informações nos processos de ensinar e aprender. É preciso aumentar o número de vozes que questionem as interpretações por demais reducionistas que distancia o currículo de sua função principal, que o afasta dos aspectos relacionados às configurações sociais da educação e das relações de poder delas decorrentes. Isto pressupõe, sem dúvida, uma discussão mais aprofundada dos aspectos ontológicos, epistemológicos e metodológicos que prevalecem na ciência, a partir das novas descobertas científicas e das novas realidades ecológicas, humanas, políticas e sócio-culturais.

Por outro lado, esta reflexão também nos leva a procurar evitar, ao máximo, os prejuízos que uma epistemologia equivocada é capaz de provocar no sistema educacional e em seus beneficiários, bem como na sociedade como um todo. Tais prejuízos ocorrem não apenas em relação aos conteúdos trabalhados, mas, principalmente, no que se refere aos prejuízos político-pedagógicos provocados por uma perspectiva teórica fragmentada, rígida, linear, reducionista presente em algumas visões curriculares estreitas e cientificamente defasadas e indefensáveis. Já não é mais tempo de propostas pedagógicas que legitimam a fragmentação do conhecimento, do ser humano, da realidade e da vida ou de concepções acríticas provocadoras de processos sociais equivocados.

Tudo isto é fundamental em termos de responsabilidade social, pedagógica e formativa, lembrando também que, na atual conjuntura, em relação aos processos formativos, um bom currículo é sempre muito importante ao trazer consigo um fortalecimento político-pedagógico da comunidade educacional envolvida, além da possibilidade de construção de uma cidadania planetária cada dia mais urgente e necessária. Ademais, saber conceituar e responder bem as questões curriculares é hoje uma das pautas mais importantes para se inserir de forma competente o Pensamento Complexo no discurso das políticas educacionais, evitando-se assim prejuízos maiores de natureza ética, política e formativa.

Observa-se também que a discussão sobre currículo sob o olhar da complexidade favorece também a aproximação dos especialistas e estudiosos da complexidade em relação às questões políticas e sociais da educação, aspectos estes ainda pouco explorados pela maioria de seus membros. Por outro lado, mediante a realização de profícuos e competentes debates, estaremos também evitando a ocorrência de alguns delírios pedagógicos por parte daqueles intelectuais que vêem na complexidade e na transdisciplinaridade uma panacéia para quase todos os males educacionais. Estaremos também evitando a construção e a imposição de possíveis 
prescrições de "modelos" de compreensão reducionistas em detrimento de processos mais contextualizados, de referenciais históricos e culturais mais adequados às necessidades formativas do pessoal envolvido. Estaremos também tentando evitar a prescrição de um "currículo uniforme” igual para todos, evitando-se assim um currículo pasteurizado, homogeneizado, aquela coisa de "tamanho único" que serve para todos, esquecendo que as situações educacionais, bem como seus objetos de estudo, implicam processos de natureza complexa, portanto, diferenciados, auto-eco-organizadores, emergentes, imprevisíveis e sujeitos ao acaso.

A partir desta compreensão, o currículo não deixa de ser um importante instrumento capaz de ancorar as mais diversas dimensões e perspectivas da ação educacional, convertendo-se em uma excelente oportunidade para se começar a plantar as sementes da reforma do pensamento proposta por Edgar Morin (1998). Nossa experiência docente ratifica que o currículo é um excelente instrumento para se discutir as questões relacionadas à complexidade e suas implicações na educação, além de ser um estímulo importante para se incentivar o pensamento relacional que a epistemologia da complexidade exige.

Mais do que nunca, precisamos de análises lúcidas, competentes e de sínteses integradoras e comprometidas com as questões sociais e ecológicas mais prementes, além de clareza epistemológica no trato das questões educacionais e um exército de vigilantes epistemológicos, competentemente preparados para evitar reducionismos, fragmentações e/ ou totalizações obscuras e descomprometidas em relação aos objetivos da educação. Todos esses aspectos e justificativas levam-nos à construção deste texto e nos motivam a introduzir este debate.

\section{Currículo: aproximação conceitual}

A palavra currículo vem do latim Curriculum que significa pista de corrida, caminho, percurso, trajetória. Palavra que indica também travessia, com seus pontos de partida e de chegada. Um caminho a ser seguido, realimentado, reorientado e bifurcado sempre que necessário pela ação dos envolvidos no cenário educacional. Mas, um caminho que, a princípio, deveria estar sujeito ao imprevisto, ao inesperado; sujeito às situações emergentes, ao acaso, à ecologia da ação, o que na maioria das vezes não acontece.

Para Silva (2005), currículo é lugar, espaço, território. É texto, discurso e documento. Mas, um documento que revela determinada identidade. Em realidade, currículo é o documento de identidade de cada escola, revelador da complexidade de seu percurso, de suas opções teóricas, de seus objetivos, de suas metas, princípios e metodologias trabalhadas. Revela também a visão de sujeito e de mundo compartilhada por determinada comunidade educacional, o conjunto de princípios que norteia suas ações, independente da área de interesse ou da especialidade de cada professor. 
Macedo (2008, p. 27), por sua vez, entende o “currículo como um complexo cultural tecido por relações ideologicamente organizadas e inventadas. Como prática potente de significação, o currículo é, sobretudo, uma prática que bifurca”. Como tal, isto significa que nem todas as rotas ou trajetórias curriculares podem ser previstas e planejadas antecipadamente, pois de acordo com o Pensamento Complexo (Morin, 1996), a realidade está sempre em movimento e existe uma multiplicidade de caminhos ou de rotas incentivadas por diversas possibilidades evolutivas.

Desta forma, em todo currículo planejado, ou no nível da ação planejada, a incerteza e a bifurcação estarão sempre presentes, já que toda e qualquer ação pode entrar no jogo das inter-retroações, da cooperação ou da recursão, podendo ou não ser desviada da rota inicialmente planejada ou dos objetivos pré-estabelecidos. Conseqüentemente, é prudente e necessário se ter abertura e flexibilidade nas estruturas curriculares planejadas e estar aberto às emergências, às bifurcações e às mudanças ocorrentes nos ambientes de aprendizagem, pois a não-linearidade e o indeterminismo podem exigir uma mudança de rota, fazendo com que uma ação, inicialmente não planejada e insignificante, possa transformar-se em algo importante e significativo em outro momento do processo.

Para Froes Burnham (1998), é preciso compreender a polissemia do termo, mas também seu significado como processo social que se realiza no espaço escolar, no sentido de oferecer aos sujeitos interagentes o acesso a diferentes referenciais de leitura e de relacionamento com o mundo, proporcionando-lhes, não apenas um lastro de conhecimentos e de outras vivências importantes para sua inserção no processo histórico, como sujeito capaz de fazer história, mas também para sua construção como sujeito que participa ativamente do processo de construção e de socialização do conhecimento e assim, dos processos histórico-sociais de sua comunidade. Para essa autora, os sujeitos, intersubjetivamente, constroem e reconstroem a si mesmos, o conhecimento produzido e as relações entre si e com a realidade que os cerca e, pela ação, transformam essa realidade a partir de processos cíclicos e recursivos que contém, em si mesmo, tanto a espiral da continuidade como a da emergência do novo.

Currículo é, portanto, o instrumento de concretização do projeto referencial da escola. Um documento que traz uma rede de referências importante, a partir da qual se tenta organizar o trabalho educacional e contribuir para a formação do sujeito aprendente, tendo em vista a construção de uma sociedade democrática. Com base no currículo, seja ele formal ou informal, explicito ou implícito, é que as escolhas são feitas, os caminhos e os percursos são traçados e vivenciados no cotidiano escolar. Mediante sua elaboração e apresentação é dada a partida para o jogo de poder que acontece dentro da escola.

Neste texto não pretendemos discutir os diferentes enfoques e propostas teóricas que predominaram ao longo das últimas décadas nas diversas proposições, criações e vivências no campo curricular. Nosso desejo 
é tentar trabalhar este texto a partir de reflexões sobre algumas implicações do Pensamento Complexo no currículo, independentemente dos rótulos modernista, pós-modernista, estruturalista ou pós-estruturalista, crítico ou pós-crítico. O que pretendemos examinar é em que aspectos a complexidade poderá contribuir para uma leitura mais adequada e competente das questões curriculares e quais são os aspectos em que a complexidade pode colaborar para a renovação da produção teórica sobre currículo, a partir de análises das temáticas consideradas emergentes e necessárias para o debate educacional na conjuntura atual.

\section{Complexidade: desvelando o conceito e justificando este novo olhar}

“...os sistemas de ensino nos ensinaram a isolar os objetos (de seu meio ambiente),

a separar as disciplinas (em vez de reconhecer suas correlações), a dissociar os problemas, em vez de reunir e integrar. Assim, obrigamnos a reduzir o complexo ao simples, isto é, a separar o que está ligado; a decompor, e não

a recompor; e a eliminar tudo que causa desordens ou contradições em nosso entendimento... O pensamento que recorta, isola, permite que especialistas

e experts tenham ótimo desempenho em seus compartimentos e cooperem eficazmente nos setores não complexos de conhecimento, notadamente os que concernem ao funcionamento das máquinas artificiais;

mas a lógica a que eles obedecem estende à sociedade e às relações humanas os constrangimentos e os mecanismos inumanos da máquina artificial e sua visão determinista, mecanicista, quantitativa, formalista; e ignora, oculta ou dilui tudo que é subjetivo, afetivo, livre e criador."

Edgar Morin, (2003, p. 15)

Complexidade significa, para Edgar Morin (1990), uma tessitura comum que coloca como sendo inseparavelmente associados o indivíduo e o meio, a ordem e a desordem, o sujeito e o objeto, o professor e o aluno e todos os demais tecidos que regem os acontecimentos, as ações e as interações que tecem a trama da vida. Para Morin (1990:20), “complexo significa aquilo que é tecido em conjunto".

Portanto, a complexidade pode ser compreendida como um princípio regulador do pensamento e da ação, aquilo que não perde de vista a realidade 
dos fenômenos, que não separa a subjetividade da objetividade e não exclui o espírito humano, o sujeito, a cultura e a sociedade (Morin, 1996). É o olhar complexo sobre os fenômenos que nos permite, segundo esse autor, encontrar um substrato comum à biologia, à física e à antropologia. É esse olhar que nos possibilita encontrar uma certa abertura epistemológica capaz de estender a noção de sistema um pouco mais além da física e da biologia, na tentativa de compreender não apenas a natureza ordenada/desordenada da matéria e o funcionamento dos sistemas vivos, mas também as organizações sociais como unidades complexas.

É o pensamento complexo que não nos permite abandonar o sujeito à sua própria sorte, sinalizando-nos que a existência de um pressupõe a presença do outro, pois ambos estão implicados e co-determinados em sua materialidade física existencial. Isto também nos indica que somos autores e, ao mesmo tempo, co-autores e co-produtores dos objetos do conhecimento, que somos influenciados pelos pensamentos e idéias dos outros e que a nossa autonomia é sempre relativa (Morin, 1996). Uma autonomia que depende das relações que construímos no ambiente onde estamos inseridos; depende dos processos auto-eco-organizadores que garantem a natureza autopoiética dos sistemas vivos, ou seja, a capacidade de autoprodução de si mesmo como condição de sua própria autonomia existencial.

É esta complexidade que também nos revela a incompletude dos processos, que nos mostra a incompletude do conhecimento e a incompletude do ser aprendente que somos. É ela que nos ensina que, simultaneamente, somos seres físicos, biológicos, sociais, culturais, psíquicos e espirituais. E todas essas dimensões envolvidas em nossa corporeidade se influenciam reciprocamente, indicando que, em todas as atividades desenvolvidas pelo ser humano, incluindo o conhecer e o aprender, essas dimensões estão presentes nos processos auto-eco-organizadores ocorrentes em nossas estruturas orgânicas. Nada acontece ao nosso espírito que não afete a nossa matéria corporal.

A complexidade seria, então, esse tecido comum, esse pano de fundo que rege os acontecimentos, as ações, as interações e retroações ocorrentes. Compreendida desta maneira, a complexidade significaria, para Morin, aquilo que está por trás ou no pano de fundo dos acontecimentos, dos eventos e fenômenos, não sendo apenas um conceito, mas um fator constitutivo da vida que responde pelo entrelaçamento existente entre os fenômenos e os processos constitutivos da dinâmica natural da própria vida.

Fundamentado no Pensamento Complexo de Edgar Morin, é possível perceber que a chave da complexidade está em compreender ou em reconhecer a união da simplificação e da complexidade, em entender o interjogo existente entre análise e síntese, sujeito e objeto, indivíduo e contexto, educador e educando, percebendo a complementaridade dos processos envolvidos na tentativa de compreender a realidade de maneira menos redutora possível. Isto porque todo fenômeno complexo é constituído por 
um conjunto de objetos inter-relacionados, por interações lineares e nãolineares. Sabemos que a linearidade existe, mas sempre como exceção e não como regra. Esta fenomenologia complexa nos diz que o todo é sempre maior ou menor do que as soma das partes e que, em um sistema qualquer, cada parte não está perdida e nem fundida ou confundida no todo, mas possui uma identidade e uma funcionalidade própria, diferente da identidade e funcionalidade do todo. Um sistema organizado não anula a diversidade, mas a incorpora.

No que se refere aos aspectos ontológicos desta construção teórica, ser e realidade funcionam a partir de uma engenharia complexa, constituída por uma dinâmica não-linear funcional em rede, de natureza recursiva ou retroativa. Uma realidade indeterminada, difusa e imprevisível, sujeita aos processos emergentes e transcendentes, à sinergia que requer situações autoeco-re-organizadoras. É uma realidade complexa e multidimensional tecida por processos não-lineares e imprevisíveis, sujeita ao acaso e ao inesperado e que, por sua vez, influencia a dinâmica de qualquer ambiente de aprendizagem. Trata-se de uma complexidade entranhada no tecido do universo e nutrida pelos mais diferentes fluxos de energia, matéria e informação que circulam. Esta mesma complexidade está também presente nos processos de ensino e aprendizagem, nos processos emergentes, interdependentes, sinérgicos, auto-eco-reorganizadores ocorrentes nos sistemas educacionais.

Assim, nossa realidade é multidimensional em sua natureza complexa, interdependente, mutável, entrelaçada pelos fluxos que acontecem no ambiente e a partir do que cada um faz. Uma realidade que é contínua, descontínua, indeterminada em sua dinâmica operacional, que se manifesta dependendo do contexto, das situações vividas e das circunstâncias criadas. O reconhecimento da existência de múltiplas realidades e a legitimidade de todas elas é algo muito importante para esta construção teórica, lembrando que a realidade surge a partir do que cada um faz, pensa, sente e age. Conscientes ou não, somos construtores, criadores e recriadores das propostas curriculares no momento de sua materialização em sala de aula.

Em relação aos aspectos epistemológicos, é importante observar que a complexidade, como fator constitutivo da vida e presente em todas as dimensões e níveis de realidade, também se apresenta nos processos de construção de conhecimento e na aprendizagem, afetando nossos esquemas lógicos e obrigando-nos a repensar o seu papel epistemológico. É um princípio-guia do pensamento e da ação que influencia nossa leitura de mundo e nos ajuda a interpretar melhor os fenômenos, os processos e os acontecimentos.

É um princípio-guia que muito colabora para o entendimento dos mecanismos funcionais do pensamento, do conhecimento e da ação humana e que traz consigo uma nova epistemologia que trabalha os conceitos de relação, de organização, de auto-organização, de mudança, de autonomia, de ecologia da ação, de emergência e de transcendência. Assim, não existe uma realidade objetiva independente da experiência subjetiva. Toda 
objetividade está impregnada de subjetividade.Todo conhecer e aprender depende do que acontece no sujeito, de como funciona sua corporeidade, já que ele está sempre banhado pelas emoções, nutrido pelas intuições, pelos sentimentos, pelas sensações e histórias de vida. Enfim, depende de tudo aquilo que acontece no ser humano. Assim, a experiência do aprendiz é sempre fundamental e dependente de suas relações com o meio, no qual estão inseridos outros sujeitos.

Conseqüentemente, o conhecimento não pertence ao cérebro, mas às relações, às coerências estabelecidas entre o sistema vivo e suas circunstâncias. Segundo Maturana (2000), cognição e vida não estão separadas, já que o conhecimento acontece no cotidiano da vida, no viver/ conviver. Para ele, aprendizagem surge a partir do acoplamento estrutural do sujeito com o mundo. É um processo que se estabelece no viver/conviver e depende das estruturas internas do sujeito e do que acontece em suas relações com o meio. Ela é única e intransferível.

Sob este ponto de vista, o aprender implica mudar com o mundo a partir de interações ocorrentes e a cognição não é representação do mundo independente do sujeito, mas sua própria criação, dependendo das mudanças estruturais que ocorrem em seu organismo e da forma como cada um experimenta o objeto do conhecimento (Maturana, 2000). O aprender acontece a partir de nossas configurações e idéias prévias e de nossas relações com o outro, mediante convivência social.

Biológica e epistemologicamente falando, podemos dizer que tudo que forma, em realidade, transforma algo em nossas estruturas, pois, segundo Maturana, "nada do que fazemos é trivial, porque somos um tempo presente em mudança” (2000:95), a partir de processos autopoiéticos. Assim, processos de formação implicam transformações e mudanças estruturais em nossa organização viva. Todo processo de formação pressupõe autoformação, em co-existência com o outro (heteroformação) e com as circunstâncias vividas (ecoformação). Todo processo formativo e de aprendizagem implica dinâmica de natureza autopoiética, ou seja, de natureza auto, eco e heteroformadora, aberta, fundada na solidariedade, no questionamento constante e nas reflexões sobre as ações desenvolvidas.

Desta forma, podemos observar que a complexidade nos diz que o currículo já não pode continuar sendo o arauto das verdades pré-programadas e nem a escola o "lócus das certezas" absolutas, já que a incerteza é inalienável ao processo e o significado de algo é socialmente construído. Ele não é pré-existente, mas construído socialmente, dinamizado culturalmente, mediante relações de poder nas quais o sujeito está implicado.

Aquele currículo da modernidade, baseado em certezas estáveis, fundado na estabilidade e na ordem, com características linear, seqüencial, estática e lógica binária já não mais se sustenta. Isto porque o pensamento complexo e transdisciplinar, nutrido pelos operadores cognitivos da complexidade e pela lógica ternária, questionam o binarismo construtor de 
um currículo com forma e conteúdos aprisionados pelo certo/errado, pelo velho/novo, pelas separações entre o que é orgânico e inorgânico, sujeito e objeto, branco e preto, mente e corpo, individual e coletivo, espírito e matéria, exigindo, por parte dos educadores, novos olhares, novas compreensões, novas percepções e novos valores e, sobretudo, novas transformações, a partir de um processo permanente de auto, hetero e ecoformação.

\section{Complexidade, subjetividade, multirreferencialidade e implicações no currículo}

É extremamente importante, sob o nosso ponto de vista, trabalhar as questões curriculares a partir de teorizações complexas, pois o currículo envolve ou deveria envolver um ambiente de mudança e de transformação, como também relações mutantes ocorrentes entre conhecimento, identidade, poder e consciência.

No centro das questões curriculares, a partir de um pensar complexo, já não está aquele sujeito apenas racional, centrado no poder, independente do contexto, autoritário e autônomo da modernidade, mas sim um sujeito pensante, constituído por uma complexidade estrutural que não separa o mental do físico, a razão da emoção, a mente da matéria e a matéria do espírito; que não separa o fato da fantasia, o passado do presente e do futuro. Está um sujeito ontologicamente esperançado, como nos diria nosso querido amigo Paulo Freire, um sujeito que é ator e autor de sua própria história e co-autor das histórias coletivas que acontecem ao seu redor. Um ser humano multidimensional em sua corporeidade, dotado de diferentes capacidades cognitivas, emocionais e espirituais e enriquecido por suas múltiplas competências e habilidades.

Sob o olhar da complexidade, a subjetividade é tecida pela articulação do individual com o social e, como configuração de sentidos e significados, vai sendo constituída a partir de múltiplos elementos e de processos ou condições nas quais a relevância de uma não pode ser entendida desprezando suas relações com a outra. Aqui, as subjetividades individual e coletiva constituem-se mutuamente, não sendo possível entender uma sem a outra, já que os processos ocorrentes nos sistemas vivos são co-determinados, coinfluenciados, refletindo a existência de relações mútuas e complementares entre eles. Da mesma forma, sujeito e objeto constituem uma totalidade e ambos somente existem relacionalmente, já que todo observador não fica de fora da realidade observada, não vê a natureza como objeto isolado, mas como elemento integrante de um mesmo e único processo muito maior.

Em relação à teoria do currículo, esse pressuposto é muito importante, pois desvela o contextualismo, bem como o poder das circunstâncias criadas nos ambientes de aprendizagem e a importância das influências sócio-culturais nos processos de construção do conhecimento. Revela ainda que a natureza ou a realidade que se manifesta depende das diversas 
interconexões, das relações e interações ocorrentes, já que o mundo macrofísico encontra-se dissolvido em feixes dinâmicos de energia, matéria e informação, caracterizadores da realidade microfísica.

Conseqüentemente, a complexidade nos ajuda a repensar a educação e o currículo a partir da pluralidade cultural, das múltiplas vozes que se entretecem, dos diferentes olhares que se cruzam, evitando com isto os processos de dominação cultural, como única via de entendimento da realidade educacional. Ou a educação é um processo de libertação e transformação ou não é educação, nos ensinava nosso querido mestre Paulo Freire, em suas inesquecíveis aulas.

Disto também resulta o caráter multirreferencial do currículo, a luta pela afirmação das diferenças, o reconhecimento da alteridade como característica importante da contemporaneidade, que coloca também em questão o enfoque da transdisciplinaridade, revelando assim que nossos saberes não são apenas nutridos ou constituídos por conteúdos disciplinares, mas também por relações que transcendem as diversas disciplinas, por relações sociais, afetivas e emocionais que refletem condições sócio-históricas e culturais importantes vividas pelos sujeitos aprendentes.

Podemos, então, observar que a diversidade de olhares, de sentido, de sensibilidade e significado, a diversidade cultural, a pluralidade, a mestiçagem, são elementos constitutivos de uma realidade complexa e se manifestam de diferentes maneiras no interior da escola, o que favorece o surgimento de múltiplas referências, de pluralidade de linguagens e possibilidades de interpretação da realidade.

Desta forma, o Pensamento Complexo exige a aceitação da diferença, o reconhecimento da pluralidade, da diversidade, das diferentes leituras de mundo, das diversas linguagens com as quais os indivíduos interpretam os fenômenos constitutivos de sua realidade. Disto se deduz que a atenção à diversidade não é apenas uma questão de adaptação ou preocupação com a normalidade curricular, mas, sim, um processo de inclusão e de transformação da realidade. Não é apenas um processo meramente de caráter ético-pedagógico, mas algo de natureza complexa em seu potencial de transformação e libertação. Assim, como trabalhar com um currículo igual para todos, como se fosse um modelo único que serve a todos igualmente? Como trabalhar com processos homogeneizadores sem o devido reconhecimento e a necessária articulação de conjuntos tão heterogêneos que continuamente promovem a elaboração de novas significações?

Daí a importância, na prática curricular, de se levar em conta a diversidade cultural, a pluralidade de referências, as múltiplas leituras e óticas diferentes, entendendo que a provisoriedade está sempre presente na dinâmica processual que permeia a complexidade dos fenômenos educacionais.

Esta visão também nos leva a compreender, da mesma forma que Macedo (2008, p. 69) que “o currículo é um artefato cultural inventado 
e seus conteúdos são produtos de uma construção social, implicando aí relações de poder para legitimar e afirmar cosmovisões.” É significativo, portanto, o papel da linguagem, das narrativas e dos discursos a partir desta construção teórica. Entretanto, é preciso associar também o caráter complexo, auto-organizador, auto-produtor e autotransformador que o currículo, como processo de natureza complexa, que também deveria trazer consigo. Assim, não podemos continuar coisificando o currículo como um artefato inventado para organizar a formação de pessoas, mas buscar compreendê-lo em sua dinâmica complexa de caráter formativo e cultural (Macedo, 2008). Desta forma, é preciso ir além da concepção reprodutora do currículo, já que a complexidade exige mais do educador. Exige que pensemos também em seu potencial auto-eco-organizador, naquelas dimensões mais esquecidas pelos educadores, ou seja, na possibilidade do currículo ser também uma porta de esperança, ontológica e epistemologicamente falando, já que nele estará também presente a dimensão auto-eco-organizadora da educação, matriz propulsora de novas emergências e transcendências no que se refere às questões educacionais.

Em relação a este processo de mestiçagem sócio-cultural influenciando os diferentes atos de currículo, tendo a complexidade permeando esta tessitura em sala de aula, é importante refletir e pensar criticamente nos diferentes tempos culturais e interpessoais que interferem nos cenários educacionais e que constituem referências importantes e condicionadoras do aprendizado dos alunos. Assim, estaremos evitando o automatismo, a homogeneização, o autoritarismo, a rigidez e a linearização dos tempos humanos nos ambientes de aprendizagem, bem como nos trabalhos pedagógicos desenvolvidos.

Portanto, a sala de aula, como um cenário educacional de natureza complexa, socialmente construída e reconstruída em função das relações que se estabelecem entre o professor, o aluno e o conhecimento, precisa ser compreendida como um microcosmo complexo, como um espaço de transformação e libertação, onde o tempo não podem ser trabalhado de modo autoritário, prepotente e reconhecido apenas em sua dimensão cronológica.

O tempo na sala de aula, a partir da epistemologia da complexidade, já não pode jogar contra a singularidade, a criatividade, as emergências ou contra os processos de aprendizagem ou de autonomia dos alunos. Pelo contrário, este tempo precisa ser considerado sempre a favor dos sujeitos aprendentes, a favor daqueles que apresentam maiores dificuldades em seus processos de construção do conhecimento e aprendizagem.

É preciso existir um tempo para oxigenar o cérebro, para facilitar a aprendizagem, para que os processos de cooperação global ocorram no organismo ou para acolher cada olhar e desenvolver a compreensão. Necessitamos de um tempo rico, interativo, a serviço de um fecundo processo de construção do conhecimento e de uma aprendizagem emancipadora, um tempo para que os processos de mediação, intermediação, negociação e 
transformação do diverso, do diferente e do heterogêneo também possam estar presentes.

É isto que a complexidade, em seu diálogo com as questões curriculares, exige de cada um de nós. Ela exige flexibilidade estrutural e que afrontemos e compreendamos o verdadeiro sentido da complexidade dos tempos vividos em sala de aula, tempos que já não podem ser controlados por uma campainha tocando de hora em hora ou por uma sineta controladora de entradas e saídas. Tempos controlados de forma policialesca e rotineira, que abortam processos criativos e ignoram as emoções e os sentimentos, já não fazem mais sentido.

Sabemos que todo processo criativo demanda um tempo para que as coisas aconteçam, para que os processos amadureçam, se materializem e os frutos possam ser colhidos. Demanda um tempo para que a sinergia aconteça, para que a convergência se faça presente e para que as interações sejam processadas. Todo processo educativo requer um tempo para a escuta sensível, para o devaneio, para a espera vigiada e atenta. Um tempo para processar as informações mais importantes e para que os processos de cooperação no interior de cada neurônio aconteçam. Há um tempo para a fecundação e outro para a espera; um tempo para a religação, para recuperação do que foi perdido, um tempo para a emergência e para a transcendência.

Desta forma, a complexidade presente em todo processo de aprender e conhecer requer a compreensão e o reconhecimento da temporalidade institucional e pessoal, sendo que a institucional, mais do que nunca, precisa estar a serviço da aprendizagem e não apenas em função dos aspectos burocráticos, políticos, rotineiros e patriarcais predominantes. Requer, portanto, uma compreensão clara da dimensão temporal do processo de aprendizagem, do tempo que já não é o do relógio externo, mas, sim, do nosso relógio interno, aquele tempo kairós que permite que as coisas aconteçam quando tem de acontecer e que, sem dúvida, também está presente no cotidiano da sala de aula e a serviço de uma prática curricular competentemente trabalhada para que as estruturas do pensamento possam emergir.

Assim, a complexidade dos processos cognitivo-emocionais e espirituais exige do professor uma atenção especial ao tempo trabalhado na sala de aula, pois tudo que acontece na corporeidade humana implica dinâmica não-linear de natureza autopoiética e complexa, cujo tempo não pode ser controlado de fora para dentro. Este cuidado é importante para que a sala de aula seja um espaço onde cada gesto ou cada ação, por mais simples que seja, possa ser habitada por um fazer consciente e amoroso que se transforme em um verdadeiro acontecimento, no qual cada expressão artística, cada raciocínio lógico, cada intuição, cada leitura e cada descoberta possam ser vividas como um acontecimento que educa, transforma e faz crescer.

Outro aspecto a ser destacado é que a complexidade desvela uma realidade constituída de padrões de interconexões, de inter-relações, ou 
seja, um padrão em rede. Isto, por sua vez, tem influências sobre o pensamento curricular ao favorecer a metáfora do conhecimento em rede ou de um currículo também em rede, um “currículo vivo”, tecido no contexto cotidiano do viver humano. Assim, em vez dos pilares disciplinares assentados na visão moderna da deusa razão, o conhecimento é tecido por redes construídas a partir dos atos do cotidiano escolar, um cotidiano que é rico, imprevisível, imponderável, incompleto e muitas vezes também estimulante, no qual os diferentes atores traduzem e redefinem suas possibilidades, seus planos, programas e projetos. Entretanto, isto não pode significar espontaneísmo, falta de atenção ou ausência de planejamento. Planos, programas e projetos precisam ser formalizados, mas como algo que possa ser reconstruído novamente na sala de aula, algo flexível, que possa ser recriado, revisitado e transformado sempre que necessário.

No cotidiano da sala de aula, a partir do currículo nutrido pela complexidade, são tecidas as redes de significados compartilhados por diferentes sujeitos, mediante as quais são construídos os conhecimentos. Mas, é um conhecimento que quebra as barreiras entre o saber científico e o saber popular, entre o conhecimento científico e as histórias de vida, pois estas também podem e devem ser colocadas a serviço da ciência, já que cada ser aprendente participa do processo com toda sua bagagem vivencial, com sua história de vida permeada pelas suas emoções e pelos seus sentimentos, dimensões presentes em sua corporeidade e nutridoras de suas memórias, de suas intuições e histórias de vida constitutivas da inteireza humana.

Desta forma, o currículo real é aquele que é praticado no cotidiano escolar e resolvido na prática do dia a dia, no diálogo teoria e prática e que, por sua vez, sofre influências das múltiplas redes de conhecimento entretecidas no burburinho da sala de aula e não por determinações legais, portarias ou currículos oficiais impostos verticalmente.

Outro aspecto importante e inspirador que a complexidade nos adverte ao trabalhar as questões curriculares refere-se à insustentabilidade do pensamento pedagógico que separa disciplinas e que apenas valoriza o pensamento abstrato e verbal e não as inteligências interpessoal, intrapessoal e espiritual do ser humano. É insustentável aquele pensamento que recorta, isola, mutila, fragmenta os objetos do conhecimento e a realidade pesquisada e que ainda continua presente na sala de aula e nos processos de reorganização curricular. Tais processos, desenvolvidos em sua maioria como projetos educacionais, normalmente não levam em consideração outras experiências e saberes importantes, outras competências e habilidades significativas, na tentativa de domesticar os processos cerebrais desenvolvidos pelo hemisfério direito, no qual predomina a criatividade, a intuição e o imaginário.

Com sua "babel” disciplinar, com suas horas-aula pré-planejadas, divisões em unidades, disciplinas e anos letivos, com seus métodos de controle e de supervisão policialescos, nutridos por mecanismos de controle, de padronização e de avaliação inadequada, nossos sistemas educacionais 
continuam fragmentando o conhecimento, isolando objetos de seus contextos, separando o inseparável, disciplinando e recortando os problemas emergentes. Tudo isto na esperança de reduzir o complexo ao simples, de conhecer para domesticar e dominar, sem perceber que muros altos e grades nas janelas não impedem o roubo e a presença das drogas nas mochilas dos alunos e chamadas e listas de presença também não garantem um corpo presente, um sujeito atento ou um espírito criativo, muito menos garantem motivação e desejo de aprender. Sabemos que não existe remédio para a apatia, para o cansaço, o tédio, a indiferença e para o descompromisso presente na sala de aula. Nada disto impede que o pensamento único e autoritário se faça presente e que os fantasmas das certezas perambulem pelas carteiras escolares, abortando processos criativos, inibindo vozes, diluindo desejos e vontades, castrando mentes brilhantes e dificultando toda e qualquer iniciativa importante e significativa por parte do aluno.

De uma visão positivista de currículo, que se traduz em um elenco de disciplinas e respectivos conteúdos fragmentados, constitutiva do hábito disciplinar tradicional e promotora das estruturas que mais predominam nos ambientes educacionais e caracterizam o atual status quo, busca-se, hoje, promover iniciativas que ajudem a compreender a complexidade envolvida nos processos de construção de conhecimento e na aprendizagem. Neste sentido, a complexidade contribui para não mais ver a disciplina como a última fronteira do conhecimento de determinada realidade ou como arquétipo da compartimentação do conhecimento na sociedade moderna (Macedo e Lopes apud Macedo, 2008).

Embora reconheçamos sua importância, já não podemos continuar isolando os atores curriculares nos espaços confinados de suas disciplinas, pois o real não é disciplinar e não se manifesta da mesma maneira como são organizadas as grades curriculares. Da mesma forma, a interdisciplinaridade e a transdisciplinaridade tampouco o é, já que a complexidade inscrita na problemática da sociedade excede os aspectos disciplinares, interdisciplinares e transdisciplinares da realidade mutante. A realidade é intrinsecamente complexa. Esta complexidade constitutiva da realidade exige um pensamento que relacione, articule e questione um pensamento que ajude o sujeito a melhor compreender as dinâmicas relacionais existentes em processos interdependentes caracterizadores da dinâmica da vida.

Neste sentido, é preciso que o currículo se transforme no espaço da solidariedade epistêmica (Macedo, 2008), diante da multiplicidade e da heterogeneidade das experiências educacionais que requerem a superação da fragmentação disciplinar e a presença do diálogo fecundo entre elas. Caso contrário, continuaremos não dando conta dos problemas que afligem a humanidade.

Para tanto, cada disciplina, com seus respectivos atores, deve passar a oferecer sua valiosa contribuição para o enriquecimento da prática pedagógica e começar a interagir umas com as outras, mediante comunicação de idéias e integração mútua de conceitos, de epistemologias, terminologias, 
metodologias, estratégias ou outros procedimentos educacionais quaisquer. Deve favorecer, sobretudo, a atitude do espírito humano para contextualizar, relacionar e globalizar, para que os jovens e os cidadãos adultos, deste milênio, possam colaborar para a regeneração de uma nova cultura, de um novo humanismo, fundado no enriquecimento mútuo entre a cultura tradicional e a cultura cientifica (Motta, 2008).

\section{Interdisciplinaridade e transdisciplinaridade}

Tais práticas educativas curriculares favorecem o surgimento da interdisciplinaridade e da transdisciplinaridade, cujos diálogos viabilizam o trabalho a partir de um projeto comum que ajuda na superação das fronteiras, que melhora a qualidade do processo pedagógico e do conhecimento nele inserido. Ambas permitem uma releitura crítica da lógica disciplinar organizadora da maioria dos currículos existentes.

Sabemos que tanto a interdisciplinaridade como a transdisciplinaridade pressupõem a relação de mutualidade, de intercâmbio, de diálogo, de integração e mudança de atitude diante do conhecimento. Ambas demandam a necessidade de se conhecer bem o objeto do conhecimento, para que dele possam ser extraídas todas as relações possíveis. Melhor dizendo, para que eles possam ser epistemologicamente esgotados, explorados ou melhor compreendidos em todas as suas dimensões.

Sabemos também que a complexidade, com seus princípios dialógico, recursivo, hologramático, é um dos eixos constitutivos tanto do conhecimento interdisciplinar como do transdisciplinar. Ambos os conhecimentos, para que possam ser materializados em sala de aula, requerem mudança de atitude, exigem abertura, diálogo, desapego e, ao mesmo tempo, ousadia, transgressão, perseverança e competência, para que possam ser superadas as dicotomias, as fragmentações, as tensões e as polaridades na busca de um conhecer mais global, profundo e abrangente.

Em nível curricular, ambos se materializam a partir de projetos, da integração de conteúdos, de temas, de metodologias etc. O que difere um conhecimento do outro é a qualidade do que está sendo construído, o nível de elaboração e de integração em que ele se apresenta, bem como a presença de alguns aspectos importantes envolvidos em sua construção como, por exemplo, a lógica ternária e os níveis de realidade presentes no conhecimento transdisciplinar.

Assim, curricularmente falando, a complexidade favorece o surgimento dos conhecimentos interdisciplinar e transdisciplinar, sendo um dos componentes de sua matriz geradora. Em função de sua natureza complexa, tais conhecimentos são sempre inacabados, transitórios, em constante vir-a-ser. Metodologicamente, isto implica o uso de enfoques unificadores, processos dinâmicos, criativos, abrangentes e profundos, fundamen- 
tados no rigor, na abertura, no diálogo e na tolerância. As estratégias pedagógicas favorecidas, tanto pela interdisciplinaridade quanto pela transdisciplinaridade, devem promover interações todo/partes, local/global, corpo/mente, cognição/emoção, educador/educando, reconhecendo a inseparabilidade existente entre esses elementos. Enfim, reconhecendo a inseparabilidade entre todos os tecidos que regem os fenômenos, os eventos e os processos educacionais.

Curricularmente, tais pensamentos nos indicam que nenhuma disciplina pode aprisionar o objeto do conhecimento ou enclausurar a realidade pesquisada, o que implica reconhecer, na prática, a legitimidade dos diferentes pontos de vistas, das múltiplas referências que emergem nos processos de construção do conhecimento.

Desta forma, a multirreferencialidade deve permear a abordagem curricular como explicado, anteriormente, caracterizando assim o surgimento do que é plural e a abolição do singular e, consequentemente, a existência de lógicas diferentes no trato do conhecimento, o uso de linguagens plurais e não somente de uma única linguagem ou o prevalecimento de um método único ou um tipo de causalidade.

É esta pluralidade, geradora de uma epistemologia pluralista e multirreferencial, que requer a abertura de nossas gaiolas epistemológicas, para que os nossos pensamentos, com suas emoções subjacentes, possam voar, fazendo com que não mais sejamos prisioneiros do nosso olhar disciplinar, de nossas certezas e verdades geradoras de arrogância e prepotência, tanto em nível pessoal como profissional.

Se permanecermos construindo conhecimento a partir de uma única disciplina, de um único e mesmo nível de realidade ou enjaulados em uma única maneira de ver as coisas, aprisionados a uma única perspectiva, sem aprender a explorar outras relações e possibilidades, estaremos, certamente, fracionando não apenas o conhecimento, mas também aprisionando e fragmentando a realidade, o ser humano, o mundo e a vida. Conseqüentemente, os níveis de percepção e de consciência dos sujeitos envolvidos também serão afetados e, com certeza, se apresentarão muito mais limitados.

Aprofundando um pouco mais nesta questão e examinando possíveis influências no currículo, sabemos que as perspectivas - interdisciplinar e transdisciplinar- exercem um papel formativo e elucidativo importante, à medida que elas não aceitam fórmulas prontas e pragmáticas de um pensamento único ou de modelos descontextualizados, mas mobilizam os processos de interdependência, de mestiçagem, de interfecundação e religação de saberes, sem, entretanto, deixar de reconhecer suas especificidades.

Um currículo transdisciplinar, nutrido pela complexidade, trabalha com projetos, com perguntas mediadoras, com questões temáticas e problemas, com ciclos de aprendizagem, trabalham também com sínteses 
integradoras, com relações contextuais, históricas e políticas, sínteses estas requeridas pela problemática humana e pelos seus desafios (Macedo, 2008; Moraes, 2008). Outro aspecto importante é que a transdisciplinaridade, nutrida pela complexidade, colabora para o enfrentamento de questões ético-políticas, epistemológicas e metodológicas relacionadas à ecoformação e à cidadania planetária, o que, por sua vez, nos informa que a lógica disciplinar não consegue dar conta em virtude dos aspectos transdisciplinares envolvidos. Por outro lado, ela procura preservar as questões relacionadas ao desenvolvimento humano, a partir da unidade complexa e da multidimensionalidade caracterizadora do ser aprendente.

É importante ainda observar que a maneira complexa de se pensar o currículo e a educação exige que trabalhemos a partir de alguns princípios do pensamento, chamados por Edgar Morin (2003), de operadores cognitivos para um pensar complexo, considerados por ele como instrumentos do pensamento que facilitam a compreensão dos fenômenos, dos problemas educacionais, mas, que sobretudo, facilitam nosso diálogo com a vida e com a realidade que nos cerca. Entre eles, estão os princípios dialógico, recursivo e hologramático, além daquele responsável pela integração do sujeito em seu processo de observação e o que o coloca como autor e ator de seu processo de construção do conhecimento, associado ao princípio da auto-eco-organização. Tais princípios não trabalham de maneira independente, mas associados uns aos outros.

\section{Finalizando}

Resumindo, podemos afirmar que o olhar complexo sobre as questões curriculares exige um planejamento flexível, aberto, com ampla margem para negociação com alunos e professores. Uma de suas características importantes é a flexibilidade estrutural que favorece o "circuito de regeneração”, facilitador da capacidade de auto-organização dos sistemas vivos. É um currículo aberto à criatividade e ao desconhecido, que acolhe o inesperado e possibilita novas emergências e incentiva nova transcendência, indo além do planejado, do esperado, no que se refere ao conhecimento e à aprendizagem. É um currículo em ação, em movimento, que dialoga com o cotidiano e com o indeterminado, que incentiva o fluxo de idéias e de informações que circulam. Um currículo em rede, sujeito às bifurcações sempre que necessárias, aos momentos de auto-eco-regulação, mediante reflexões individuais e coletivas. Um currículo onde toda ação é sempre uma ação ecologizada (Morin, 2003), sujeita às interações, às incertezas e a não-linearidade processual.

Isto de certa forma coloca em questão um problema epistemológico importante para o conhecimento e para toda e qualquer ação educacional, ao exigir uma mudança na nossa maneira de pensar e agir, ou como quer Edgar Morin, ao pedir uma reforma do pensamento que, em nossa opinião, deveria vir sempre acompanhada por maior abertura do coração, já que o domínio da complexidade é também o da solidariedade, o da tessitura em 
comum, o da responsabilidade social e o da inclusão, em todas as suas dimensões.

Vale ainda a pena destacar a necessidade urgente de se restaurar o que Morin e seus colaboradores (2009) falam a respeito da inteligência da complexidade nas nossas culturas e nos nossos sistemas educacionais, pois em todos os domínios do conhecimento, a complexidade surge como o tecido que permeia o mundo dos fenômenos sejam eles sociais ou não.

A inteligência da complexidade, portanto, é hoje uma necessidade vital para os indivíduos, as culturas e as sociedades, em geral. Sua presença é condição para nos conduzirmos bem na vida. Sem ela, nossa humanidade não irá muito longe. Daí a importância de se trabalhar em educação o paradigma da complexidade e, em especial, no que se refere às questões curriculares, para que possamos, além de oxigenar as disciplinas, provocar a convergência de olhares e de atenções em direção à reforma do pensamento educacional e, consequentemente, à mudança paradigmática.

Assim, inúmeros esforços neste sentido serão sempre muito bemvindos, já que a complexidade ajuda a introduzir outra maneira de pensar e de tratar o real e que, entre outros aspectos, traz consigo as dimensões da imprevisibilidade, da incerteza, da diversidade na unidade e viceversa. Estas dimensões requerem maior esforço por parte da inteligência humana ao demandar uma reforma do pensamento nutrida pelos princípios e operadores cognitivos e, ao mesmo tempo, pela crítica e pela elaboração própria.

Neste sentido, realmente entendemos que um currículo bem trabalhado é a porta de entrada da esperança para melhoria da educação, pois nos ajuda a ver os objetos do conhecimento a partir de um sistema complexo sem reduzi-lo, simplificá-lo ou descontextualizá-lo. É esta inteligência que nos ajuda a conectar, a pensar organizacional e relacionalmente, a ligar uma disciplina à outra, a contextualizar o objeto de conhecimento, a religar dados, informações e conhecimentos separados, dando-lhes um novo sentido e redescobrindo novos significados, a partir de uma circularidade construtora e promotora de novas possibilidades.

A inteligência da complexidade nos mostra que o real não é um reflexo da realidade, mas sua tradução ou reconstrução a partir do cérebro/ espírito humano (Morin e Le Mogné, 2009). Para tanto, necessita de uma nova epistemologia capaz de religar o fazer e o compreender, a ética e a estética, o saber científico e o saber popular ou uma disciplina à outra.

Todos esses aspectos, de uma maneira ou de outra, interferem nas relações aluno/professor, em seus processos de mediação/socialização/ construção do conhecimento. Assim, trabalhar a relação complexidade/currículo faz uma grande diferença no que se refere ao desenvolvimento da consciência dos sujeitos aprendentes, bem como nos seus processos de inserção como sujeitos que fazem história e que participam ativamente dos 
processos de construção do conhecimento e de socialização do que foi construído.

Trabalhar o currículo, a partir do Pensamento Complexo, é hoje um dos suportes teóricos importantes que ratifica a importância das questões curriculares no processo educacional como um todo e, em especial, para a construção de novos valores mais condizentes com as necessidades atuais. Entretanto, para nós educadores, não resulta fácil calibrar todos os aspectos aqui enfocados em nossa prática curricular, embora todo esforço neste sentido seja importante e necessário, condição fundamental para que possamos enfrentar os graves problemas emergentes, em suas mais variadas formas e dimensões. É condição para que nos situemos de uma maneira mais inteligente no mundo e na vida, pois o conduzir-se bem na vida, o posicionar-se adequadamente diante dela e de todos os desafios que ela nos coloca, depende da educação recebida. A maneira como educamos e acreditamos que deva ser o processo de construção do conhecimento e a aprendizagem depende muito de como pensamos e compreendemos a realidade, da clareza ontológica e epistemológica que tenhamos ou não.

Desta forma, precisamos tomar consciência sobre a necessidade de uma nova compreensão acompanhada de uma nova ética, mas de uma ética ecológica, a ética do respeito, da solidariedade, da convivência; a ética das relações que reconhece a interdependência dos fenômenos, a ética que nos une e, ao mesmo tempo, renova nossos compromissos e obrigações com as futuras gerações. Obrigações que também envolvem deveres e responsabilidades em relação à natureza e ao cosmo. Necessitamos, pois, de novos valores, de novas linguagens, de novas compreensões para lidar com a realidade educacional e de uma ética diferenciada que verdadeiramente nos ajude a sobreviver como espécie, a afrontar nosso cotidiano e a ser mais felizes em nossa humanidade.

Los científicos, como los poetas, muestran que las trayectorias de la naturaleza y de la humanidad son indisociables, que nuestra comunidad de origen es idéntica a nuestra comunidad de destino.

Morin y Hulot (2008:117). 


\section{Bibliografía}

Batalloso Navas, J. M. (2010), Dimensiones de la Psicopedagogia hoy: Una visón transdisciplinar, LiberLivro. (No prelo), Brasilia.

Froes Burnham, T. (1998), “Complexidade, multirreferencialidade, subjetividade: três referências polêmicas para a compreensão do currículo escolar”, en Barbosa. J. (Org.), Reflexões em torno da abordagem multirreferencial, EdUFS, São Carlos, Car.p. 35-55.

Macedo, R. S. (2008), Currículo: campo, conceito e pesquisa, Editora Vozes, Petrópolis/RJ.

Maturana, H. (1997), La objetividad: Un argumento para obligar, Dolmen Ediciones, Santiago.

Idem (2000), Transformación en la convivencia, Dolmen Ediciones, Santiago.

Moraes, M. C. (2008), Ecologia dos saberes: Complexidade, transdisciplinaridade e educação, Antakarana/ProLibera, São Paulo.

Idem (2004), Educar na biologia do amor e da solidariedade, Editora Vozes, Petrópolis/RJ.

Morin, E. (1990), O Paradigma perdido: a natureza humana, Publicações Europa América, Sintra/Portugal.

Idem (1990), Introdução ao pensamento complexo, Instituto Piaget, Lisboa.

Morin, E. et al. (1996), O problema epistemológico da Complexidade, Publicações Europa-América, Sintra/Portugal.

Morin, E. (1996), “Epistemologia da complexidade”, em Schnitman, D. F. (org.) Novos paradigmas e cultura e subjetividade, Artes Médicas, Porto Alegre.

Morin, E. \& Prigogine, Y. (1998), A sociedade em busca de valores: para fugir às alternativas entre cepticismo e o dogmatismo, Instituto Piaget, Lisboa.

Morin, E. (1998), Ciência com consciência, Bertrand Brasil, Rio de Janeiro.

Idem (2003), A cabeça bem-feita: repensar a reforma, reformar o pensamento, $8^{\text {a }}$ ed. Bertrand Brasil, Rio de Janeiro.

Morin, E. \& Hulot, N. (2008), El año I de la era ecológica, Ediciones Paidós, Barcelona. 
Morin, E. \& Le Mogné, J.L. (2009), Inteligência da complexidade: Epistemologia e pragmática, Instituto Piaget, . Lisboa.

Motta, R. D. (2008), Filosofía, complejidad y educación en la era planetaria, UANL, San Nicolás de los Garza, N.L..

Silva, T. T. (2005), Documentos de identidade: uma introdução às teorias do currículo, $2^{\mathrm{a}}$. Ed., Autêntica, Belo Horizonte. 